\title{
Peningkatan Akurasi Klasifikasi Ketidaktepatan Waktu Kelulusan Mahasiswa Menggunakan Metode Boosting Neural Network
}

\author{
I Ketut Putu Suniantara ${ }^{1}$, Gede Suwardika ${ }^{2}$, Siti Soraya ${ }^{3}$ \\ ${ }^{1}$ Program Studi Sistem Informasi - ITB STIKOM Bali \\ ${ }^{2}$ Prodi Statistika - UPBJJ Denpasar - Universitas Terbuka \\ ${ }^{3}$ Prodi Ilmu Komputer - Universitas Bumigora \\ ${ }^{1}$ suniantara@stikom-bali.ac.id, 2isuwardika@ecampus.ut.ac.id, \\ ${ }^{3}$ sitisorayaburhan@universitasbumigora.ac.id \\ DOI 10.30812/varian.v3i2.651
}

\section{INFO ARTIKEL}

\section{Riwayat Artikel:}

Diterima: 29-02-2020

Disetujui: 01-04-2020

\section{Kata Kunci:}

Tingkat akurasi

Klasifikasi

Boosting

Network

Feedforward Neural

Network
Neural

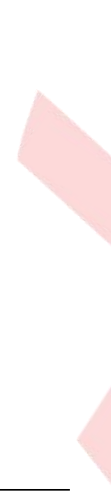

\begin{abstract}
ABSTRAK
Abstrak: Supervised learning pada Meachine learning digunakan untuk mengatasi permasalahan klasifikasi dengan pendekatan Artificial Neural Network (ANN). ANN memiliki sedikit kelemahan dalam proses operasi dan training jika jumlah data yang besar dan tidak adanya aturan khusus dalam menentukan struktur ANN, sehingga menghasilkan akurasi klasifikasi yang belum maksimal. Hasil akurasi klasifikasi Artificial Neural Network akan lebih baik dengan menggunakan boosting. Penelitian ini bertujuan untuk mengembangkan model klasifikasi Boosting Feedforward Neural Network (FFNN) yang dapat diimplementasikan dan digunakan sebagai bentuk model klasifikasi yang menghasilkan akurasi lebih baik, khususnya dalam klasifikasi ketidaktepatan kelulusan mahasiswa Universitas Terbuka. Hasil penelitian menunjukkan tingkat akurasi yang dihasilkan dengan metode Feedforward Neural Network (FFNN) memiliki tingkat akurasi sebesar 72,93\%. Penerapan boosting pada FFNN menghasilkan tingkat akurasi yang paling baik yaitu 74,44\% pada iterasi 500 .
\end{abstract}

\begin{abstract}
Supervised learning in Machine learning is used to overcome classification problems with the Artificial Neural Network (ANN) approach. ANN has a few weaknesses in the operation and training process if the amount of data is large, resulting in poor classification accuracy. The results of the classification accuracy of Artificial Neural Networks will be better by using boosting. This study aims to develop a Boosting Feedforward Neural Network (FANN) classification model that can be implemented and used as a form of classification model that results in better accuracy, especially in the classification of the inaccuracy of Terbuka University students. The results showed the level of accuracy produced by the Feedforward Neural Network (FFNN) method had an accuracy rate of 72.93\%. The application of boosting on FFFN produces the best level of accuracy which is $74.44 \%$ at 500 iterations.
\end{abstract}

\section{A. LATAR BELAKANG}

Supervised learning pada machine learning merupakan proses untuk membangkitkan sebuah fungsi yang memetakan data input sesuai keinginan dari data output. Metode ini berfokus pada bagaimana menciptakan suatu algoritma yang mempunyai suatu pola sebagai informasi dalam proses learning (Zhang, 2010).

Metode Supervised learning yang sering digunakan yaitu Artificial Neural Network (ANN). Metode Artificial Neural Network digunakan dalam pengenalan pola atau masalah klasifikasi. Klasifikasi itu sendiri merupakan sebuah teknik yang dilakukan untuk memprediksi kelas setiap input data. Implementasi klasifikasi dapat ditemui pada berbagai bidang kehidupan manusia. Sebagai contoh pada kasus kesehatan 
untuk membantu dokter dalam diagnosa penyakit, pada kasus keuangan untuk klasifikasi resiko kredit dari debitur, dalam multimedia digunakan untuk pengenal wajah manusia, pengenalan suara, dan masih banyak lagi.

Proses learning pada model ANN didasarkan pada proses pelatihan/pembelajaran yang terprogram untuk mengatur inputan yang digunakan sebagai pemataan pada bagian output sehingga diperoleh moden ANN. Contoh model ANN dapat Gambar 1.

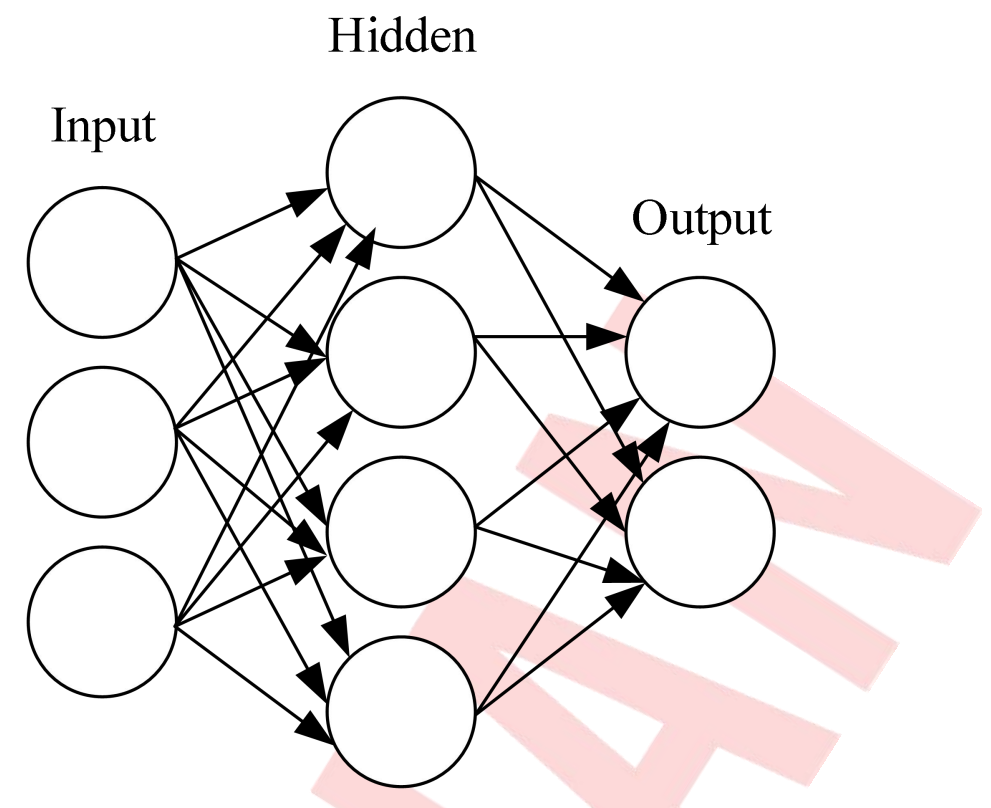

Gambar 1. Model Neural Network

Model ANN terdiri dari lapisan input, lapisan output dan kemungkinan satu atau lebih lapisan tersembunyi (hidden layer). Artificial Neural Network (ANN) itu sendiri memiliki berbagai metode untuk pengklasifikasian. Metode yang umum digunakan adalah propagasi balik (backpropagation). Algoritma backpropagation digunakan untuk menyelesaikan kasus dalam model Feedforward Neural Network (FFNN). Model FFNN merupakan neural network yang memiliki struktur satu input layer, hidden layer satu atau lebih dan satu output layer.

Metode FFNN memiliki kelebihan dibandingkan metode yang lain karena dapat digunakan untuk kasus dengan hubungan antara data input dan output yang komplek (Singh \& Chauhan, 2009). Selain kelebihan tersebut, ANN juga memiliki kekurangan yaitu tidak ada aturan khusus untuk menentukan struktur ANN. Struktur jaringan yang tepat dicapai melalui pengalaman dan coba-coba (eksperimen), sehingga akurasi klasifikasi dari ANN belum maksimal (Mijwel, 2018) (Wu, Ren, Li, Kwak, \& Jang, 2009).

Peningkatan akurasi klasifikasi ANN dapat dilakukan dengan menggunakan metode Boosting. Metode Boosting merupakan salah satu metode Ensemble yang digunakan untuk meningkatkan akurasi prediksi dari classifier yang tidak stabil (Wezel \& Potharst, 2007). Penelitian tentang boosting pada CART (Classification and Regression Tree) pernah dilakukan oleh Sueardika dkk yang menyatakan bahwa metode Boosting mampu meningkatkan akurasi klasifikasi CART(Suwardika, Suniantara, \& Hendayanti, 2019).

Penelitian dilakukan oleh Yanti dalam prediksi stok obat dengan metode Neural Network menyatakan bahwa Neural Network mampu memberikan solusi dalam melakukan prediksi stok obat dalam setahun(Yanti, 2011). Penelitian dengan metode yang sama dilakukan oleh Rifai untuk memprediski penyakit jantung menjelaskan bahwa mampu meningkatkan akurasi sebesar 91,45\%(Rifai, 2013). Sedangkan menurut Warsito dalam penelitiannya yang membandingkan FFNN dengan Generalized Regression Neural Network (GRNN) menjelaskan bahwa Model GRNN mempunyai arsitektur yang kebih kompleks dan lebih unggul dalam ketepatan prediksi dari pada model FFNN(Warsito, 2006).

Peningkatan akurasi klasifikasi yang dilakukan oleh Somantri dan Wiyono dengan menggabungkan jaringan syaraf tiruan-Algoritma Genetika mampu meningkatkan akurasi klasifikasi dari 85,46\% menjadi 85,75\%(Somantri \& Wiyono, 2017). Dalam penelitian yang sama, dilakukan oleh Muzakkir dkk menyatakan 
bahwa Backpropagation berbasis Particle Swarm Optimization lebih akurat dalam prediksi pelanggan hilang telekomunikasi dibandingkan dengan Backpropagation dengan tingkat akurasi $86.05 \%$ dan nilai AUC adalah 0,637(Muzakkir, Syukur, \& Dewi, 2014). Penelitian tentang prediksi kelulusan mahasiswa dengan metode Neural Network itu sendiri pernah dilakukan oleh Kusumawati dkk dalam penelitiannya menyatakan bahwa akurasi prediksi kelulusan mahasiswa mencapai tingkat akurasi 87.31\%(Kusumawati, Winarno, \& Arief, 2015).

Penelitian ini bertujuan untuk mengembangkan model klasifikasi Boosting FFNN yang dapat diimplementasikan dan digunakan sebagai bentuk model klasifikasi yang menghasilkan akurasi lebih baik, khususnya dalam klasifikasi ketidaktepatan kelulusan mahasiswa Universitas Terbuka.

\section{B. METODE PENELITIAN}

Tahapan penelitian yang dilakukan untuk klasifikasi ketidaktepatan kelulusan mahasiswa pada metode Feedforward Neural Network sehingga menghasilkan klasifikasi yang memiliki tingkat akurasi yang tinggi. Tahapan penelitian ini diberikan pada Gambar 2, yang merupakan ringkasan proses masing-masing sub proses sebagai berikut:

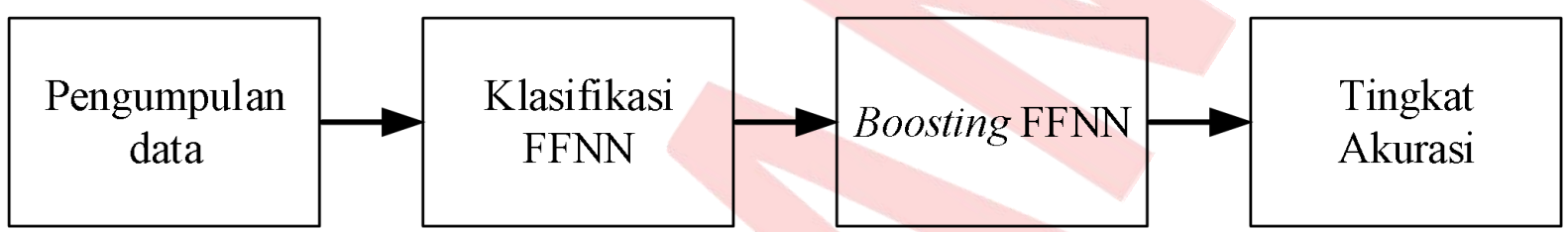

Gambar 2. Tahapan Penelitian

\section{Pengumpulan Data}

Data yang digunakan dalam penelitian ini adalah data sekunder, yaitu data lulusan mahasiswa Universitas Terbuka (UT) periode 2017 - 2018 dengan jumlah sampel sebanyak 133 wisudawan. Data ini terdiri dari variabel dependen yaitu status kelulusan mahasiswa dan variabel prediktor yang terdiri dari: Jurusan/prodi, IPK, Lama menyusun skripsi (hari), Jenis Kelamin, Asal SMA/daerah, Nilai Ujian Nasional/NEM, Pendidikan Orang Tua (bapak dan ibu) dan pekerjaan orang tua (bapak dan ibu). Adapun gambaran umum variabel dependen dan variabel prediktor dapat dilihat pada Tabel 1.

Tabel 1. Variabel Penelitian

\begin{tabular}{llll}
\hline $\begin{array}{c}\text { N } \\
\mathbf{0}\end{array}$ & \multicolumn{1}{c}{ Variabel } & \multicolumn{1}{c}{ Jenis } & \multicolumn{1}{c}{ Kategori } \\
\hline 1 & Status kelulusan mahasiswa & Diskrit & $\begin{array}{l}\text { - tepat waktu } \\
\text { - tidak tepat waktu }\end{array}$ \\
\hline 2 & Jenis kelamin mahasiswa & Diskrit & $\begin{array}{l}\text { - Laki-laki } \\
\text { - Perempuan }\end{array}$ \\
\hline 3 & Jurusan/Prodi mahasiswa & Diskrit & - \\
\hline 4 & Asal SMA mahasiswa & Diskrit & $\begin{array}{l}\text { Bali (Kabupaten dan } \\
\text { kodia) } \\
\end{array}$ \\
& & & Luar Bali \\
\hline 5 & Lama skripsi mahasiswa (hari) & Kontinu & - \\
\hline 6 & IPK & Kontinu & - \\
\hline 7 & Pendidikan orang tua & Diskrit & \\
\hline 8 & Pekerjaan orang tua & Diskrit & \\
\hline 9 & Nilai Ujian Nasional/NEM & Kontinu & \\
& & &
\end{tabular}




\section{Klasifikasi FFNN dan Boosting FFNN}

Klasifikasi metode FFNN yang dilanjutkan dengan proses boosting pada ketidaktepatan kelulusan mahasiswa dengan langkah-langkahnya sebagai berikut:

a. Melakukan klasifikasi dengan metode FFNN dengan banyak neuron yang digunakan 2, 3, 4, dan 5 .

b. Menetukan hasil klasifikasi FFNN yang terbaik berdasarkan banyak neuron pada hidden layer.

c. Melakukan pembobotan pada variabel dependen dengan $w_{i}=1 / N$ dimana $i=1, \cdots, N$ Variabel bebas yang digunakan dalam proses boosting adalah variabel prediktor yang juga digunakan dalam FFNN.

d. Tentukan jumlah iterasi $\mathrm{M}$ yang digunakan. Dalam penelitian ini jumlah iterasi yang digunakan adalah 50, 100, 200, 500 .

e. Mengklasifikasikan variabel respon yang telah diboboti dengan variabel prediktor dengan menggunakan metode FFNN dengan banyak neuron yang telah didapatkan pada langkah kedua.

f. Menghitung pengamatan yang misklasifikasi $\operatorname{err}_{m}$ untuk menghitung

$\alpha_{m}=\frac{1}{2} \ln \left(\frac{1-e r r_{m}}{e r r_{m}}\right)$

g. Ulangi langkah ke (e) sampai langkah ke ( $f$ ) sampai dengan banyak iterasi yang ditentukan.

h. Mendapatkan prediksi final dari boosting FFNN dan menghitung tingkat akurasi dari boosting FFNN.

Secara umum tahapan analisis data sebagai berikut:

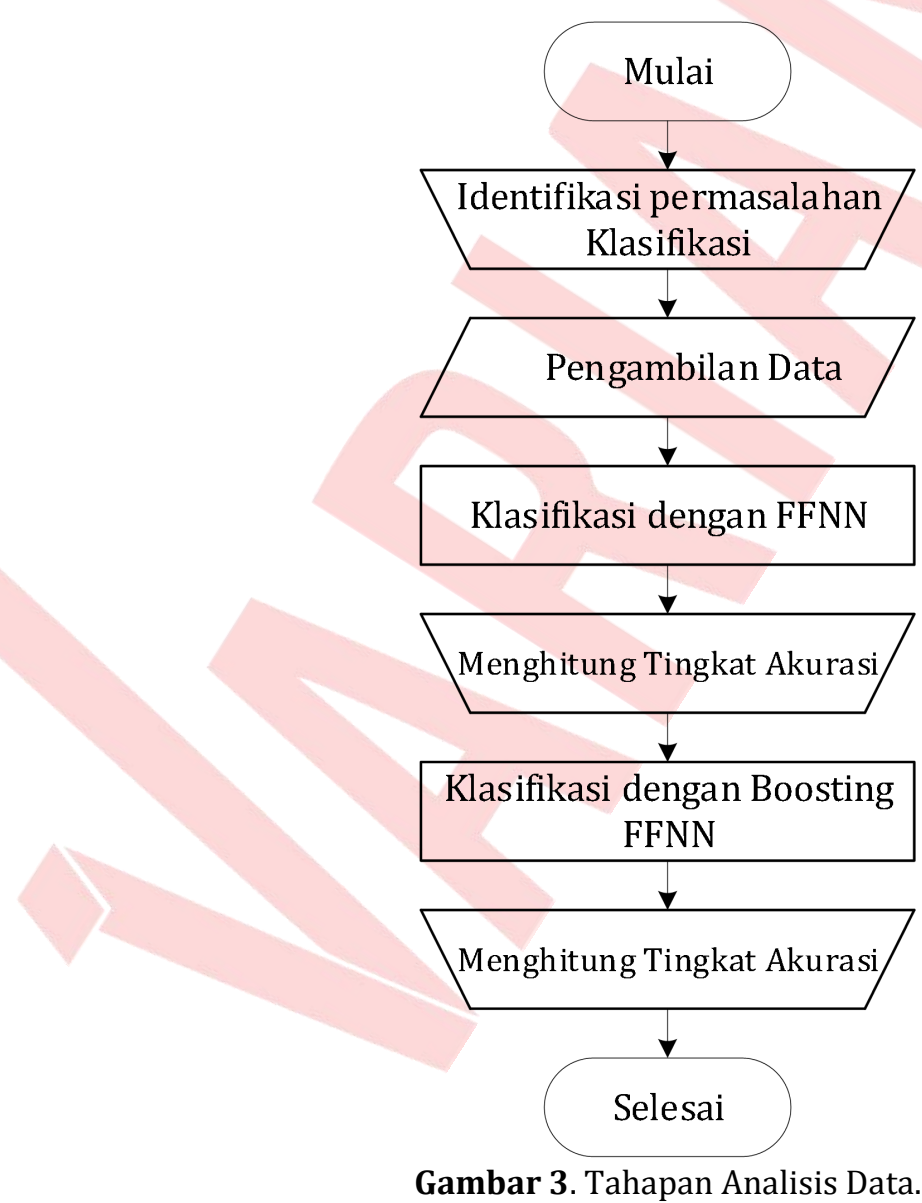

\section{Tingkat Akurasi}

Penghitungan akurasi klasifikasi dilakukan untuk melihat seberapa besar pengelompokkan sekumpulan data untuk digolongkan dengan tepat pada kelompoknya dengan menggunakan confusion matrix yaitu perhitungan kelas prediksi dengan kelas sebenarnya dari inputan nilai True Negative (TN), True Positive (TP), False Negative (FN), False Positive (FP), dan False Positive (FP). Confusion matrix dikembangkan oleh Powers yang disajikan dalam Tabel 2(Powers, 2011). 


\begin{tabular}{cccc}
\hline & & \multicolumn{2}{c}{ Kelas Sebenarnya } \\
\cline { 2 - 4 } & & $\mathbf{y}_{\mathbf{1}}=\mathbf{- 1}$ & $\mathbf{y}_{\mathbf{2}}=\mathbf{1}$ \\
\hline Kelas & $h_{1}=-1$ & $T N$ & $F N$ \\
\cline { 2 - 4 } Prediksi & $h_{2}=1$ & $F P$ & $T P$ \\
\hline
\end{tabular}

dimana:

TN : jumlah $h_{1}$ dari hasil klasifikasi yang tepat disklasifikasi sebagai $y_{1}$ FP : jumlah $h_{2}$ dari hasil klasifikasi yang salah disklasifikasi sebagai $y_{1}$ FN : jumlah $h_{1}$ dari hasil klasifikasi yang salah disklasifikasi sebagai $y_{2}$ TP : jumlah $h_{2}$ dari hasil klasifikasi yang tepat disklasifikasi sebagai $y_{2}$ Maka perhitungan akurasi klasifikasi berikut:

Accuracy $=\frac{T P+T N}{T P+F P+T N+F N}$

\section{HASIL DAN PEMBAHASAN}

\section{Klasifikasi Feedforward Neural Network}

Penentuan jumlah neuron pada klasifikasi dengan FFNN dapat dilakukan dengan cara coba-coba. Hal ini karena ketentuan yang pasti tentang berapa jumlah neuron yang tidak digunakan tidak jelas. Pada penelitian ini jumlah neuron yang digunakan adalah 2, 3, 4, dan 5. Dengan jumlah neuron yang digunakan berbeda-beda diharapkan memberikan hasil yang berbeda pula. Contoh perhitungan tingkat akurasi dapat dilihat pada Tabel 3:

Tabel 3. Klasifikasi pada Jumlah Neuron 2

\begin{tabular}{cccc}
\hline & & \multicolumn{2}{c}{ Kelas Sebenarnya } \\
\cline { 3 - 4 } & & Tepat waktu & tidak tepat waktu \\
\hline Kelas & tepat waktu & 82 & 40 \\
\cline { 2 - 4 } Prediksi & tidak tepat waktu & 3 & 8 \\
\hline
\end{tabular}

Perhitungan accuracy pada klasifikasi dengan jumlah neuron 2, sebagai berikut:

$$
\text { Accuracy }=\frac{8+82}{133}=0,6767
$$

Tingkat akurasi klasifikasi waktu kelulusan mahasiswa UT masing-masing jumlah neuron dapat dilihat pada Tabel 4. Pada Tabel 4, dapat diketahui bahwa untuk metode FFNN dengan jumlah neuron 5 memiliki tingkat akurasi yang paling baik yaitu sebesar 72,93\%. FFNN dengan menggunakan neuron sebanyak 4 akan digunakan sebagai base learner untuk proses boosting.

Tabel 4. Tingkat Akurasi Metode FFNN masing-masing Neuron

\begin{tabular}{ccccc}
\hline Metode & $\begin{array}{c}\text { Jumlah } \\
\text { Neuron }\end{array}$ & $\begin{array}{c}\text { Jumlah pengamatan } \\
\text { diklasifikasi }\end{array}$ & $\begin{array}{c}\text { Jumlah Pengamatan } \\
\text { misklasifikasi }\end{array}$ & $\begin{array}{c}\text { Tingkat } \\
\text { akurasi (\%) }\end{array}$ \\
\hline \multirow{3}{*}{ FFNN } & 2 & 90 & 43 & 67,67 \\
\cline { 2 - 5 } & 3 & 92 & 41 & 69,17 \\
\cline { 2 - 5 } & 4 & 95 & 38 & 71,43 \\
\hline & 5 & 97 & 36 & 72,93 \\
\hline
\end{tabular}

Confusion matrix untuk metode FNNN dengan 4 neuron dapat dilihat pada Tabel 5. 
Tabel 5. Confusion Matrix FFNN dengan 4 Neuron

\begin{tabular}{cccc}
\hline \multicolumn{2}{c}{ Metode FFNN dengan $\mathbf{4}$} & \multicolumn{2}{c}{ Kelas Sebenarnya } \\
\cline { 2 - 4 } Neuron & tepat waktu & Tepat waktu & tidak tepat waktu \\
\cline { 2 - 4 } Kelas & tidak tepat waktu & 2 & 34 \\
Prediksi & 24 & 13 \\
\hline
\end{tabular}

\section{Boosting Feedforward Neural Network}

Melakukan boosting pada Feedforward Neural Network dengan 4 neuron sebagai base learning dilakukan dengan iterasi boosting yang berbeda-beda. Proses boosting dilakukan dengan jumlah iterasi mulai dari iterasi 50, 100, 200 dan 500. Tingkat akurasi klasifikasi boosting FFNN dapat dilihat pada Tabel 6.

Tabel 6. Tingkat Akurasi Boosting FFNN

\begin{tabular}{cccc}
\hline Iterasi & $\begin{array}{c}\text { Jumlah pengamatan } \\
\text { diklasifikasi }\end{array}$ & $\begin{array}{c}\text { Jumlah Pengamatan } \\
\text { misklasifikasi }\end{array}$ & $\begin{array}{c}\text { Tingkat akurasi } \\
\text { (\%) }\end{array}$ \\
\hline 50 & 97 & 36 & 72,93 \\
100 & 97 & 36 & 72,93 \\
200 & 98 & 35 & 73,68 \\
500 & 99 & 34 & 74,44 \\
\hline
\end{tabular}

Pada Tabel 6, dapat dilihat bahwa metode boosting dapat meningkatkan tingkat akurasi dari FFNN. Pada proses boosting dengan iterasi 50 dan 100 pengamatan yang misklasifikasi sebanyak 36 pengamatan. Sedangkan dengan iterasi 200, tingkat akurasi meningkat dengan pengamatan yang misklasifikasi sebanyak 35, dan pada boosting dengan banyak iterasi 500 memberikan tingkat akurasi yang paling baik dengan pengamatan yang misklasifikasi sebanyak 34 pengamatan dengan tingkat akurasi 74,44\%. Dari hasil ini dapat ditarik kesimpulan bahwa boosting dapat meningkatkan akurasi dari FFNN dengan 4 neuron pada hidden layer-nya.

\section{SIMPULAN DAN SARAN}

Berdasarkan pembahasan yang telah dilakukan diperoleh kesimpulan sebagai berikut:

1. Tingkat akurasi yang dihasilkan dengan metode Feedforward Neural Network sebesar 72,93\% dengan jumlah neuron 5 .

2. Untuk penerapan metode boosting pada metode Feedforward Neural Network didapatkan tingkat akurasi sebesar $74,44 \%$ pada iterasi 500 .

3. Penerapan metode boosting pada metode metode Feedforward Neural Network mampu meningkatkan tingkat akurasi dari metode tersebut.

Peningkatan akurasi klasifikasi ini masih bisa diperbaiki dengan replikasi bootstrap yang lebih banyak.

\section{UCAPAN TERIMA KASIH}

Terima kasih disampaikan kepada Universitas Terbuka yang telah memberi dukungan finansial terhadap penelitian ini, sehingga penulis dapat menyelesaiakan penelitian ini dengan baik dan tepat waktu. 


\section{REFERENSI}

Kusumawati, D., Winarno, W. W., \& Arief, M. R. (2015). Prediksi kelulusan mahasiswa menggunakan metode neural network dan particle swarm optimization. In Seminar Nasional Teknologi Informasi dan Multimedia 2015 (pp. 6-8).

Mijwel, M. M. (2018). Artificial Neural Networks Advantages and Disadvantages. Retrieved from https://www.researchgate.net/publication/323665827_Artificial_Neural_Networks_Advantages_and_D isadvantages

Muzakkir, I., Syukur, A., \& Dewi, I. N. (2014). PENINGKATAN AKURASI ALGORITMA BACKPROPAGATION DENGAN SELEKSI FITUR PARTICLE SWARM OPTIMIZATION DALAM PREDIKSI PELANGGAN TELEKOMUNIKASI YANG HILANG. Jurnal Pseudocode, 1(1), 1-12.

Powers, D. M. W. (2011). Evaluation: from precision, recall and F-measure to ROC, informedness, markedness and correlation. International Journal of Machine Learning, 37-63.

Rifai, B. (2013). Algoritma Neural Network Untuk Prediksi Penyakit Jantung. Techno Nusa Mandiri, IX(1), 1-9.

Singh, Y., \& Chauhan, A. S. (2009). Neural Networks in Data Mining. Journal of Theoretical and Applied Information Technology, 5(6), 37-42.

Somantri, O., \& Wiyono, S. (2017). Peningkatan Akurasi Klasifikasi Tingkat Penguasaan Materi Bahan Ajar Menggunakan Jaringan Syaraf Tiruan Dan Algoritma Genetika. Jurnal Teknologi Dan Sistem Komputer, 5(4), 147-152. https://doi.org/10.14710/jtsiskom.5.4.2017.147-152

Suwardika, G., Suniantara, I. K. P., \& Hendayanti, N. P. N. (2019). Ketidaktepatan waktu kelulusan mahasiswa universitas terbuka dengan metode boosting cart. Jurnal varian, 2(2), 37-46. https://doi.org/10.30812/varian.v2i2.361

Warsito, B. (2006). Perbandingan Model Feed Forward Neural Network Dan Generalized Regression Neural Network Pada Data Nilai Tukar Yen Terhadap Dolar AS. In Prosiding SPMIPA. (pp. 127-131).

Wezel, M., \& Potharst, R. (2007). Improved Customer Choice Predictions using Ensemble Methods. European Journal of Operational Research, 181(1), 436-452. Retrieved from https://www.sciencedirect.com/science/article/abs/pii/S0377221706003900

Wu, G., Ren, Y., Li, Y., Kwak, H., \& Jang, S. (2009). Research on Parameter Optimization of Neural Networ. International Journal of HybridInformation Technology, 2(1), 81-90.

Yanti, N. (2011). Penerapan Metode Neural Network Dengan Struktur Backpropagation Untuk Prediksi Stok Obat Di Apotek(Studi Kasus: Apotek Abc). In Seminar Nasional APlikasi Teknologi Informasi 2011 (SNATI 2011) (Vol. 2011, pp. 17-18).

Zhang, Y. (2010). New Advance in Machine Learning. Croatia: In-Tech. 
102 | Jurnal Varian| Vol. 3, No. 2, April 2020, Hal. 95-102 